\title{
Influência de defeitos e diferentes processos de fabricação nas propriedades mecânicas finais de cerâmicas
}

\section{(Influence of defects and different processes of manufacture on the final mechanical properties of ceramics)}

\author{
D. Schuller ${ }^{\text {, E. C. Bianchi }}$, P.R.Aguiar ${ }^{2}$ \\ ${ }^{I}$ Departamento de Engenharia Mecânica, ${ }^{2}$ Departamento de Engenharia Elétrica, \\ Universidade Estadual Paulista, Bauru, SP \\ schuller.unesp@yahoo.com.br,bianchi@feb.unesp.br,aguiarpr@feb.unesp.br
}

\begin{abstract}
Resumo
Os materiais cerâmicos são atualmente cada vez utilizados como opção na engenharia mundial. Por se tratar de materiais com alta resistência mecânica, possuem muitas aplicações em diversas áreas, como por exemplo a de mancais, a automotiva (sensores, isoladores, catalisadores, pistões, válvulas, revestimentos), a de implantes biocompatíveis (dentário, substituição óssea, válvulas cardíacas), a de produtos sujeitos ao desgaste (guias), a de refratários (revestimento de equipamento bélico, componentes de fornos), a eletrônica, e outras. Nos processos de fabricação da cerâmica há uma gama de fatores que contribuem para as características do produto final. Devido a isso, muitos pesquisadores têm trabalhado no estudo da influência de determinados defeitos e técnicas de produção de cerâmicas nas características do produto final. Este trabalho tem como objetivo fazer uma revisão bibliográfica de recentes artigos que analisam a influência de fatores como velocidade de queima, surgimento de trincas, porosidade, fases cristalinas, e tamanho de partículas, nas propriedades mecânicas finais das cerâmicas. Pode-se concluir que é possível aperfeiçoar o processo de fabricação da cerâmica a fim de promover as melhores propriedades mecânicas possíveis, conhecendo-se fatores prejudiciais e métodos adequados para se obter o melhor produto final.
\end{abstract}

Palavras-chave: cerâmicas, processo de fabricação, propriedades mecânicas.

\begin{abstract}
Currently, the ceramic materials are widely used as options in the engineering world. Because they are materials with high mechanical strength, they have many applications in several areas like: bearings components, automotive (sensors, insulators, catalysts, pistons, valves, coatings), biocompatible implants (dental, replacement bone, heart valves), products subject to wear (guides), refractories (coating of military equipment, components of ovens), electronics, and others. In ceramic manufacturing there are many factors that contribute to the final features of the product. In this way many researchers have been working on the influences of defects and production technique on the final mechanical properties. This work has as objective to review the recent literature that study the influence of some factors like burn rates, crack growth, porosity, crystalline phases and particles size on the final mechanical characteristics of ceramics. We may conclude that is possible to improve the manufacturing process to promote the best possible mechanical properties knowing the harmful factors and the best techniques to take the optimized final products.
\end{abstract}

Keywords: ceramics, manufacturing process, mechanical properties.

\section{INTRODUÇÃO}

As características de corpos cerâmicos são decorrentes de sua composição química e do processo de fabricação da cerâmica que lhe deu origem, como temperatura de queima, quantidade de determinados componentes e também tamanho médio de grãos utilizados na fabricação. Defeitos como trincas e porosidade não desejada são decisivos para a qualidade final do produto [1-2].

Durante o processo de fabricação das cerâmicas, especificamente em sua queima, reações termicamente ativas se processam no interior da massa cerâmica promovendo a formação das fases determinantes para características mecânicas na fase final do processo [3].

As matérias primas usadas no fabrico de cerâmicos tradicionais podem ser de três tipos, levando em conta o papel que desempenham durante o processamento e o modo como afetam as propriedades tecnológicas: plásticos (argilas), fundentes (feldspato) e inertes (quartzo). A variação de quantidade de cada um destes componentes promove uma gama de possibilidades de propriedades mecânicas [4].

Este trabalho tem como objetivo estudar o surgimento e a influência de alguns defeitos e processos de fabricação na qualidade final cerâmica, contribuindo assim para o aperfeiçoamento da fabricação garantindo as qualidades mecânicas necessárias. 


\section{Influências negativas às propriedades mecânicas finais}

Alguns dos principais fatores prejudiciais às propriedades mecânicas de uma cerâmica são surgimentos de trincas e porosidade indesejada. Os motivos de surgimento e suas respectivas influências serão apresentados.
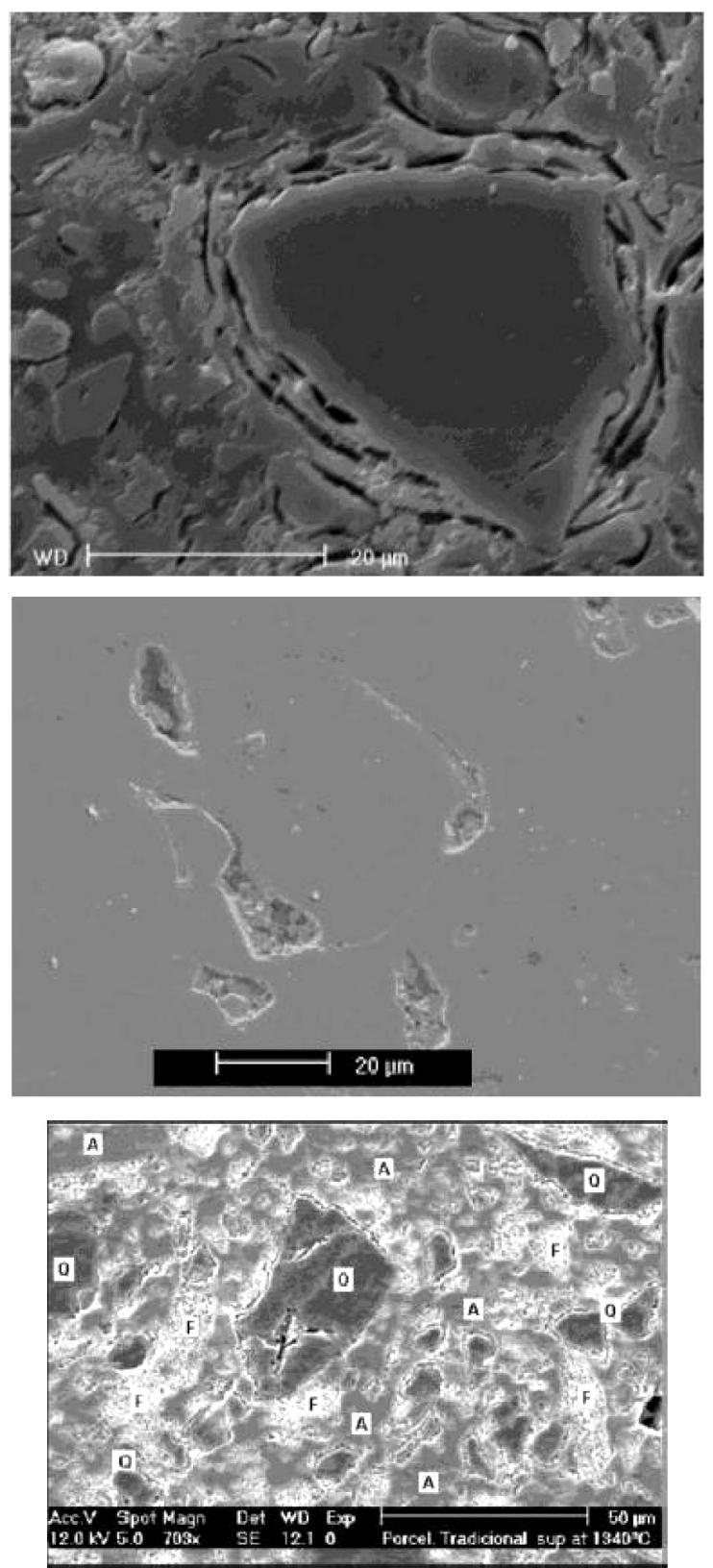

Figura 1: Fotomicrografias obtidas em microscópio eletrônico de varredura: (a) trincas periféricas ao redor do quartzo, ataque com ácido fluorídrico a $20 \%$ por $10 \mathrm{~s}$ a $20{ }^{\circ} \mathrm{C}$ [5]; (b) sem ataque ácido [5]; (c) aumento de 700x da superfície da amostra queimada a 1340 ${ }^{\circ} \mathrm{C}$ e atacada com HF $20 \%$ por 10 s $(\mathrm{Q}=$ quartzo, $\mathrm{A}=$ relicto de argila e $\mathrm{F}=$ relicto de feldspato) [2].

[Figure 1a: SEM photomicrographs: peripheral cracking on quartz grain after (a) fluoridric acid etch 20\% [5]; (b) no acid etch [5]; (c) (700x) sample surface fired at $1340{ }^{\circ} \mathrm{C}$ and etched with hydrofluoridric acid $20 \%$ for 10 s. $Q=$ quartz; $A=$ clay relict $; F=$ feldspar relict [2].]

\section{Surgimento de trincas}

Um dos motivos propostos para a ocorrência de trincas nos materiais cerâmicos é a diferença dos coeficientes de expansão térmica entre a matriz e as fases cristalinas, o que prejudica muito as propriedades mecânicas do material. Se com a variação de temperatura as partículas contraem mais que a matriz, isso resulta em pequenas trincas ao redor das partículas, como é possível observar nas Figs. 1a-1c. [2, 5].

\section{Porosidade}

Cerâmicas porosas possuem grande aplicação como isolantes térmicos para altas temperaturas pois não têm boa capacidade de transmissão de calor. Existem praticamente dois tipos de porosidade em corpos cerâmicos: aberta e fechada [6]. A porosidade aberta é a que tem contato com a superfície externa do material, a fechada a que se encontra dentro do material. Ambas as porosidades são importantes para diferentes aplicações do material na engenharia. Os materiais de porosidade aberta têm uma de suas aplicações na fabricação de filtros, já os de porosidade fechada são empregados também como materiais isolantes. Como o processamento de porcelanas é feito principalmente pela tecnologia do pó, podem ocorrer frações de poros involuntárias (indesejáveis) ou também pode-se obtê-la voluntariamente principalmente por adição de materiais orgânicos na cerâmica [3-7].

A utilização de dois tipos de feldspato (sódico e de potássio) foi comparada experimentalmente [8]. Foi constatado que quando utilizadas combinações entre $60 \mathrm{e}$ $40 \%$ de feldspato sódico em substituição do potássio, há porosidade fechada devido à excessiva formação de fase líquida. Porém a natureza do feldspato utilizado na massa de partida não afeta a proporção de quartzo que se dissolve nem a quantidade de mulita formada Sanchez [9].

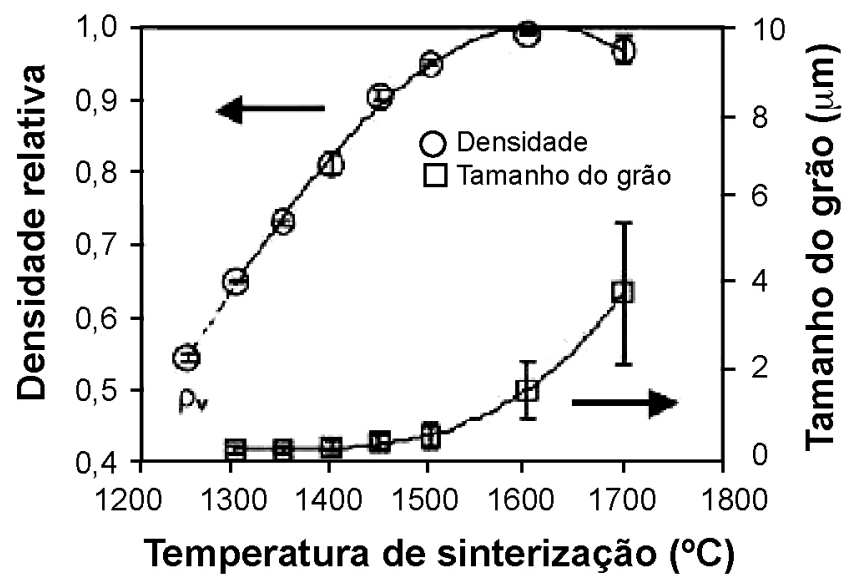

Figura 2: Densidade relativa e tamanho de grão das amostras sinterizadas entre 1300 e $1700{ }^{\circ} \mathrm{C} ; \varrho_{\mathrm{v}}$, densidade a verde. [7] [Figure 2: Relative density and grain size of simples sintered between 1300 and $1700{ }^{\circ} \mathrm{C} ; \varrho_{v}$, green density [7].] 
Foi constatado que a utilização do método de heterocoagulação para obtenção de cerâmicas porosas garante melhor qualidade às peças fabricadas [10]. Esse método baseia-se em ocorrência de coagulação ordenada, pois as matérias orgânicas e inorgânicas devem apresentar cargas opostas, sendo assim ocorre o recobrimento das partículas orgânicas pelas inorgânicas.

As características mecânicas de alumina de elevada
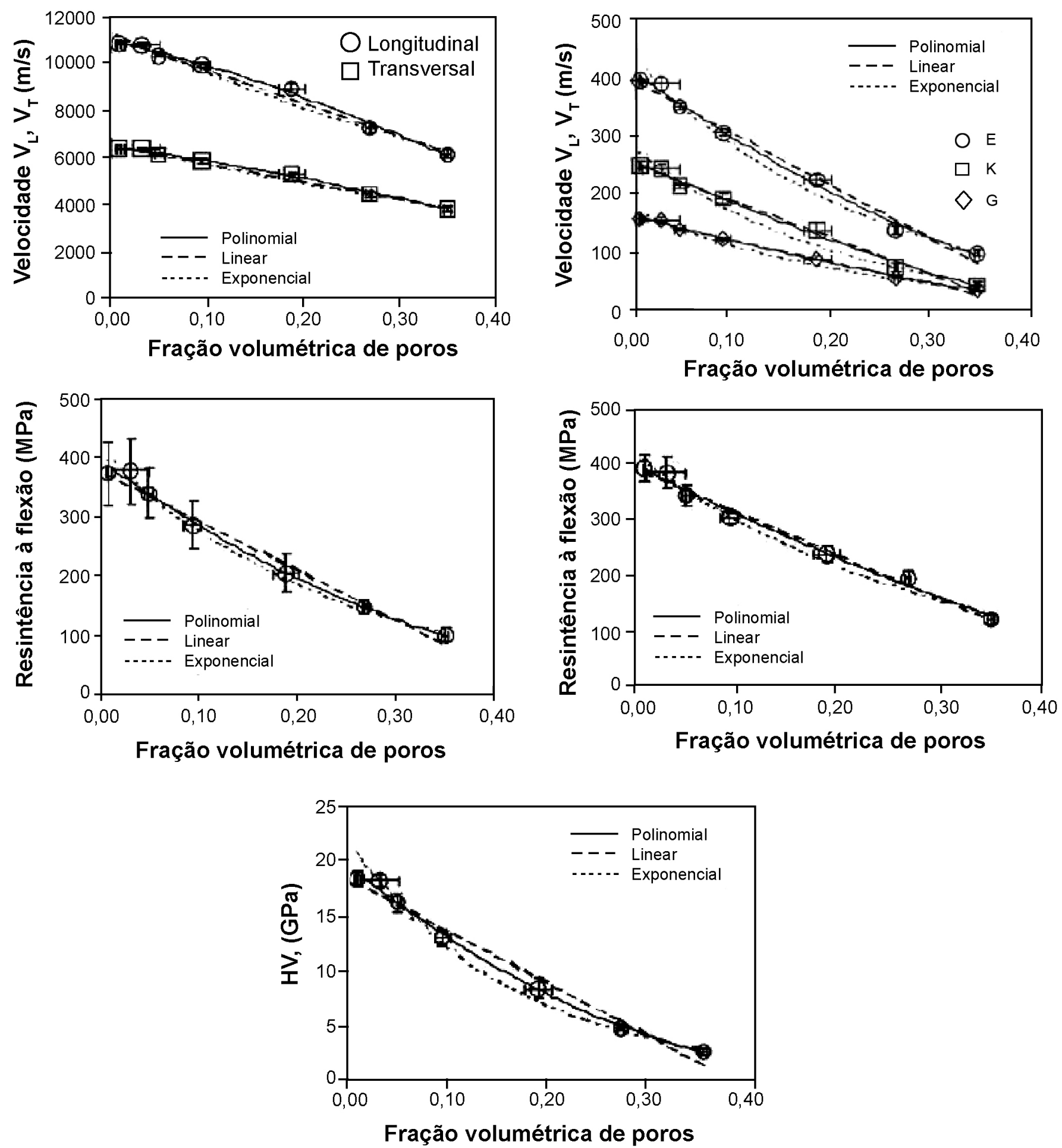

Figura 3: Dependência com a porosidade de: (a) Velocidades sônica longitudinal $\left(\mathrm{V}_{\mathrm{L}}\right)$ e transversal $\left(\mathrm{V}_{\mathrm{T}}\right)$; (b) Módulos de Young (E), de cisalhamento $(\mathrm{G})$ e volumétrico $(\mathrm{K})$; (c) Resistência à flexão em quatro pontos $(\sigma)$; (d) Tenacidade à fratura $\left(\mathrm{K}_{\mathrm{Ic}}\right)$; Dureza Vickers $\left(\mathrm{HV}_{\mathrm{I}}\right)$ [7].

[Figure 3: Porosity dependence of: $(a)$ longitudinal $\left(V_{L}\right)$ and transverse $\left(V_{T}\right)$ sonic velocities; $(b)$ Young modulus $(E)$, shear module $(G)$ and volumetric module $(k)$; (c) flexural strength at four points $(\sigma) ;(d)$ fracture toughness $\left(K_{I c}\right)$; $(e)$ hardness Vickers $\left(H V_{I}\right)$ [7].] 
Tabela I - Resultados experimentais: porosidade aparente (PA) e absorção de água (AA) dos corpos de prova de acordo com a porcentagem de matéria orgânica utilizada [3].

Table I - Experimental results: Apparent porosity (PA) water absorption (AA) of the bodies agreeing with organic percent used. [3]

\begin{tabular}{|c|c|c|c|c|c|c|c|}
\hline \multirow{2}{*}{$\begin{array}{l}\text { Temperaturas } \\
\text { Propriedades }\end{array}$} & & \multicolumn{2}{|c|}{$1100{ }^{\circ} \mathrm{C}$} & \multicolumn{2}{|c|}{$1150^{\circ} \mathrm{C}$} & \multicolumn{2}{|c|}{$1200^{\circ} \mathrm{C}$} \\
\hline & & $\mathrm{PA}(\%)$ & $\mathrm{AA}(\%)$ & $\mathrm{PA}(\%)$ & $\mathrm{AA}(\%)$ & $\mathrm{PA}(\%)$ & $\mathrm{AA}(\%)$ \\
\hline \multirow[t]{4}{*}{ Misturas } & $0 \%$ & 28,13 & 12,79 & 22,16 & 9,64 & 17,51 & 7,41 \\
\hline & $10 \%$ & 34,77 & 18,61 & 34,74 & 16,86 & 30,98 & 14,69 \\
\hline & $20 \%$ & 50,88 & 25,33 & 44,82 & 23,65 & 41,67 & 21,45 \\
\hline & $30 \%$ & 54,86 & 31,30 & 51,71 & 29,01 & 49,47 & 27,12 \\
\hline
\end{tabular}
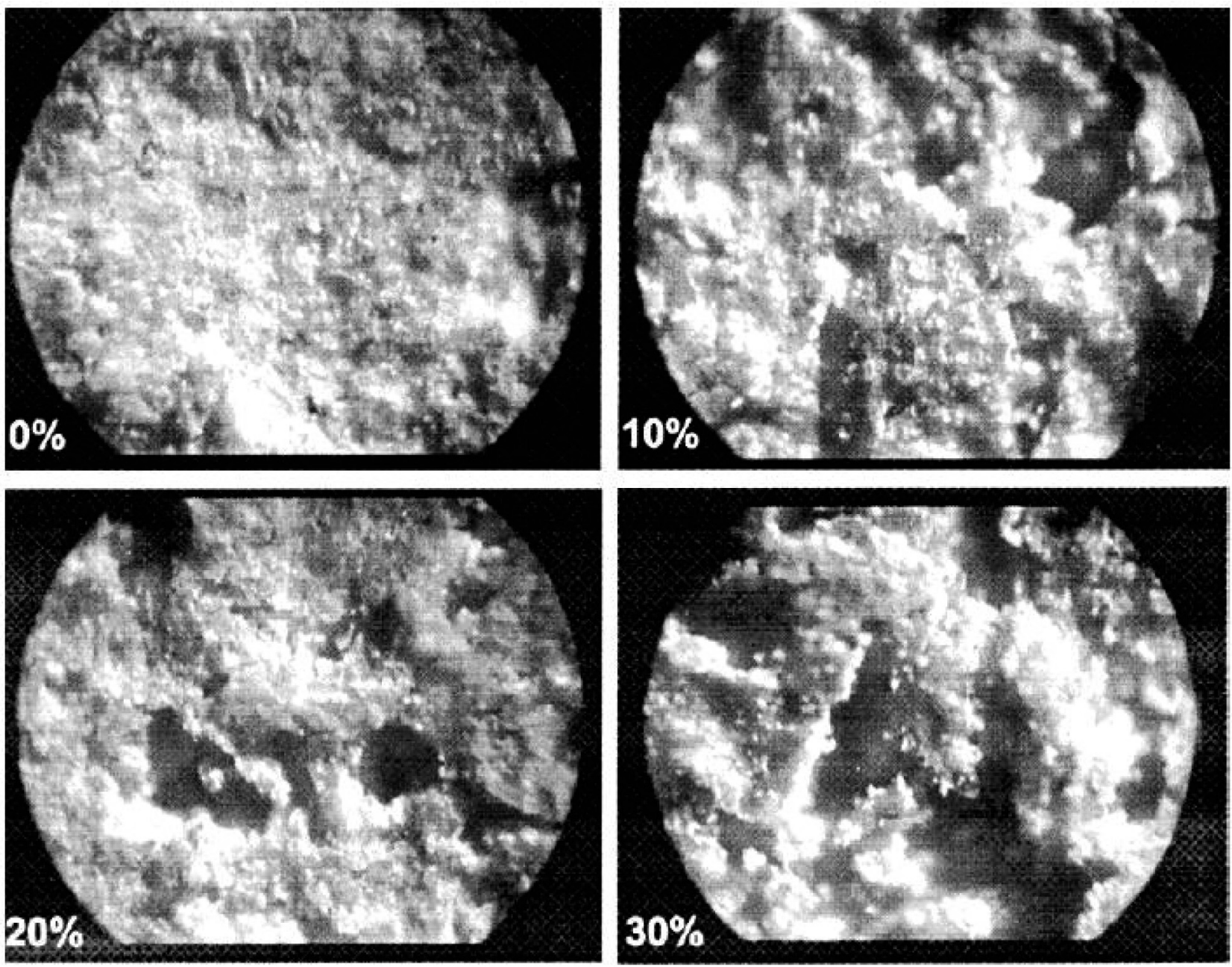

Figura 4: Micrografias ópticas do material poroso de acordo com a porcentagem de matéria orgânica aplicada [3]. [Figure 4: Optical micrographs of the porous material according to the percentage of organic material [3].]

pureza sinterizadas entre $1300^{\circ} \mathrm{C}$ e $1700{ }^{\circ} \mathrm{C}$ para preparação de amostras com diferentes porosidades foram analisadas [7]. A densidade aumentou rapidamente entre $1300 \mathrm{e}$ $1500^{\circ} \mathrm{C}$ chegando ao valor máximo $(99,2 \%$ da densidade teórica) em $1600{ }^{\circ} \mathrm{C}$ e iniciando a diminuição a $1700{ }^{\circ} \mathrm{C}$.

Até $1450{ }^{\circ} \mathrm{C}$ os corpos apresentavam porosidade aberta e os grãos não tiveram crescimento anormal até mesmo em
$1700{ }^{\circ} \mathrm{C}$; portanto, a diminuição da densidade nessa região deve ser devido à ocorrência de crescimento e coalescimento de poros em altas temperaturas, que leva à diminuição da pressão interna dos gases (aumento do raio dos poros) e, conseqüentemente à diminuição da densidade, Fig. 2.

$\mathrm{Na}$ análise de resistência à flexão, tenacidade à fratura, velocidades sônicas, módulos de elasticidade e dureza de 
acordo com a fração volumétrica dos poros observa-se que os valores apresentaram crescimento com o aumento da temperatura entre $1300{ }^{\circ} \mathrm{C}$ e $1600{ }^{\circ} \mathrm{C}$, enquanto os resultados a $1700{ }^{\circ} \mathrm{C}$ se mantiveram próximos aos de 1600 ${ }^{\circ} \mathrm{C}$. Com isso conclui-se que a porosidade até $3,1 \%$ e o maior tamanho de grão das amostras sinterizadas a 1700 ${ }^{\circ} \mathrm{C}$ em relação às sinterizadas à $1600{ }^{\circ} \mathrm{C}$ pouco afetam as propriedades mecânicas.

Também foi possível concluir que em geral velocidade sônica, módulo de elasticidade, resistência à flexão, tenacidade e dureza diminuem com o aumento da porosidade, sendo menos acentuadas nas velocidades sônicas e mais acentuadas na dureza (Figs. 3a-e). Porém, nem todos os tipos de poros são prejudiciais às propriedades mecânicas da porcelana; uma porosidade praticamente esférica numa matriz altamente densificada pode aumentar a resistência mecânica do material [5].

A variação da porosidade de acordo com a quantidade de matéria orgânica empregada ao corpo cerâmico foi analisada [3]. Concluiu-se que a oxidação da matéria orgânica ocorre entre temperaturas de 200 e $500{ }^{\circ} \mathrm{C}$ e quanto maior a sua quantidade maior a porosidade, Tabela I e Fig. 4.

No experimento notou-se que não foi possível o controle quanto à formação dos poros no corpo cerâmico com o método utilizado, podendo surgir porosidade aberta ou fechada dependendo apenas da localização do material orgânico no material.

\section{Influências positivas às propriedades mecânicas finais}

As propriedades mecânicas que um corpo cerâmico possui têm influência direta de sua composição química e forma de fabricação. A seguir são estudados alguns dos principais fatores que são essenciais para garantir boas propriedades ao material cerâmico fabricado.

\section{Fases cristalinas}

As fases cristalinas têm influencia direta na resistência mecânica das porcelanas principalmente pela sua microestrutura. O surgimento de alguns sistemas cristalinos é originário da própria queima da massa cerâmica e também no período de resfriamento. Se no ciclo de queima a temperatura necessária para fusão das fases cristalinas é atingida ou superada a taxa de resfriamento afeta de maneira significativa a quantidade de cristais formados, porém se a temperatura atingia é inferior ou insuficiente o resfriamento pouco afetará a fração cristalizada [11]. As principais fases cristalinas de uma porcelana são o quartzo e a mulita. O quartzo é o mais abundante mineral da terra e possui estrutura cristalina trigonal composta por tetraedros de sílica. A mulita é um silicato de alumínio $\left(3 \mathrm{Al}_{2} \mathrm{O}_{3} \cdot 2 \mathrm{SiO}_{2}\right)$ e existe na natureza apenas como uma raridade mineralógica (ilha de Mull, daí o nome), sendo obtida artificialmente por fusão ou pela reação no estado sólido (sinterização). À medida que se aumenta a quantidade de mulita cristalizada, aumenta-se a tenacidade da peça [9]. Em um corpo cerâmico a mulita se divide em dois tipos, mulita primária e secundária.

A formação da mulita primária é uma consequiência direta da decomposição do caulim com o aumento de temperatura. A formação da mulita secundária dá-se na fase vítrea formada pela fusão do feldspato, sendo fortemente influenciada pela viscosidade e composição química da fase vítrea [2]. Mulita primária foi descrita como em forma de um agregado de cristais de pequenas dimensões $(<0,5 \mu \mathrm{m})$ formada na região da argila, e mulita secundária, como em forma característica de uma agulha prismática formada na região do feldspato [2]. Também é afirmado que a mulita secundária se origina a partir da superfície externa da mulita primária e cresce na região de menor viscosidade (relicto do feldspato), Fig. 5.

Porém ao analisar essa afirmação, com magnitude

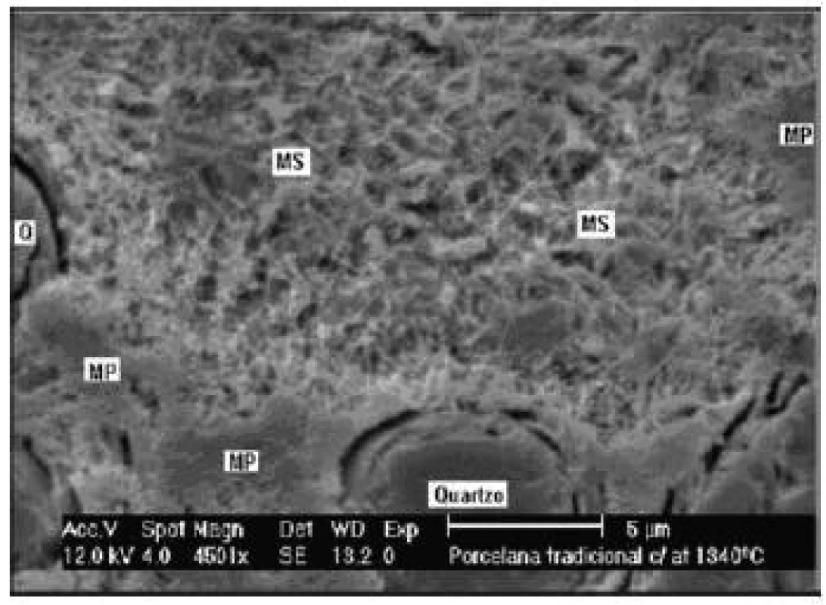

Figura 5: Fotomicrografia em MEV da superfície da amostra queimada a $1340{ }^{\circ} \mathrm{C}$ e atacada com ácido (HF $20 \%$ por 10 s). MP = mulita [2].

[Figure 5: SEM photomicrograph of sample surface fired at $1340{ }^{\circ} \mathrm{C}$ and etched with $\mathrm{HF} 20 \%$ for $10 \mathrm{~s} . \mathrm{MP}=$ primary mullite and $M S$ = secondary mullite [2].]

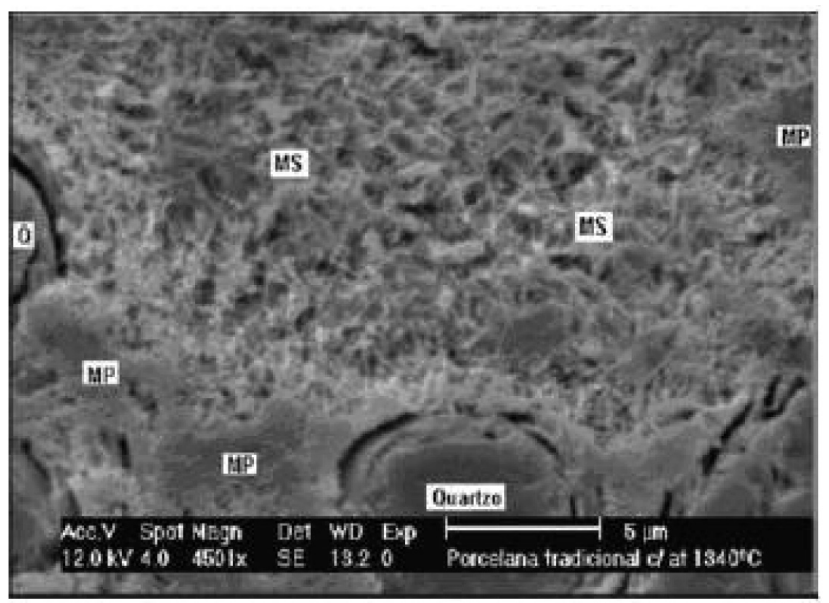

Figura 6: Fotomicrografia em MEV (900x) da superfície da amostra queimada a $1340{ }^{\circ} \mathrm{C}$ e atacada com HF $20 \%$ por 10s [2].

[Figure 6: SEM photomicrograph (900x) of sample surface fired at $1340{ }^{\circ} \mathrm{C}$ etched with $\mathrm{HF} 20 \%$ for 10 s [2].] 
ainda maior, como mostrado na Fig.6, não há necessidade de contato direto entre partículas de mulita primária e secundária. Também podem-se observar que as partículas de mulita primária possuem direção aleatória em relação à mulita secundária e partículas de possivelmente relíctos de feldspato podem ser encontradas por baixo das agulhas.

A partir disso, conclui-se que a mulita secundária se forma nos relictos de feldspato, cristalizando-se na matriz vítrea. Esta por ser líquida, permite elevada difusão, portanto mesmo regiões mais afastadas da mulita primária podem adquirir composição química necessária e consequentemente potencial químico necessário para o crescimento de agulhas, não dependendo necessariamente da primaria, porém, a hipótese de surgimento a partir da primária não é totalmente descartada.

\section{Velocidade de queima}

Foi demonstrado que a velocidade de queima de cerâmicas tem influência direta nas propriedades mecânicas [12]. Aplicando dois tipos de queima (rápido e lento) com temperaturas variando de 1080 a $1160{ }^{\circ} \mathrm{C}$ observou-se que a microestrutura sinterizada das amostras queimadas em um ciclo rápido é muito semelhante àquela sinterizada usando ciclo de queima lento, porém também se comprovou que as peças submetidas à queima lenta apresentaram tensão de ruptura e massa específica aparente superiores às queimadas em ciclo rápido, como mostra as Figs. 7 e 8 . A explicação para esse fato é que neste tipo de ciclo o material fica mais tempo exposto a altas temperaturas e conseqüentemente favorece a formação de fases cristalinas. Porém conclui-se que essas diferenças não são tão significativas em termos de propriedades e menor temperatura, o que explica a preferência por ciclos de queima rápido do setor de revestimentos cerâmicos.

Por microscopia eletrônica foi analisada a sequiência de

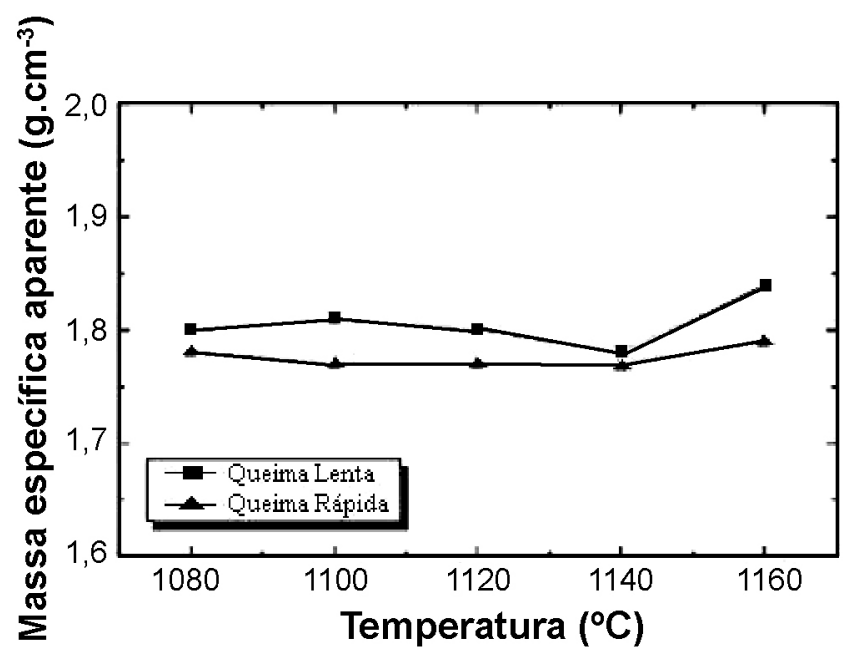

Figura 7: Massa específica aparente em função da velocidade de queima [12].

[Figure 7: Apparent specific mass as a function of burn rate [12].]

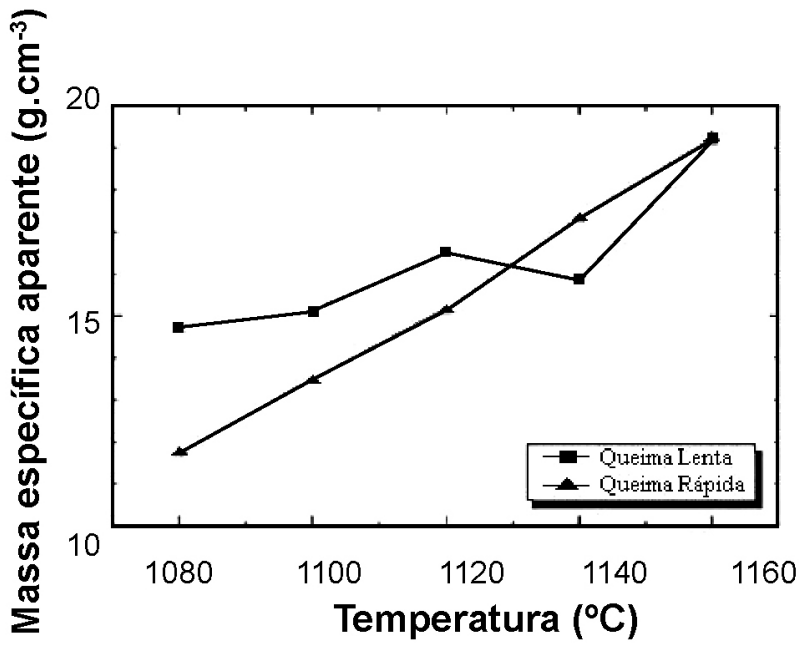

Figura 8: Tensão de ruptura à flexão em função da velocidade de queima [12].

[Figure 8: Flexural strength as a function of burn rate [12].]

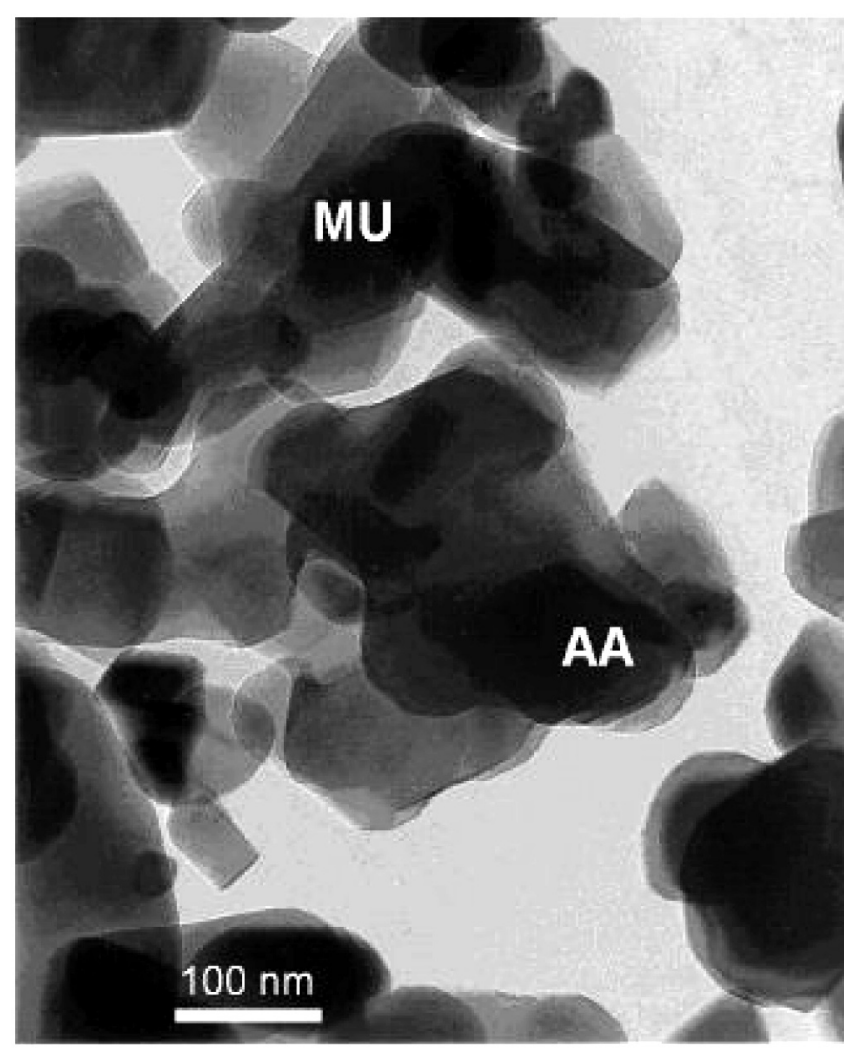

Figura 9: Argila Batalha após queima a $1300^{\circ} \mathrm{C}$ : microcristais ripiformes de mulita 3:2 (MU) e de alumina-alfa (AA) com perfil arredondado [13].

[Figure 9: Batalha clay after burned at $1300{ }^{\circ} \mathrm{C}$; lath-like $3: 2$ mullite (MU) and rounded profile alpha-alumina microcrystals (AA) [13].]

transformações ocorrentes em argilas altamente aluminosas para diferentes temperaturas de queima $\left(200\right.$ a $\left.1500{ }^{\circ} \mathrm{C}\right)$ [13]. Observou-se que a reflexão basal de gibbsita decresce com queima a $200{ }^{\circ} \mathrm{C}$ e praticamente desaparece a $300{ }^{\circ} \mathrm{C}$, confirmando dados de temperatura de transformação para esse composto [13]. Até a temperatura de $1200{ }^{\circ} \mathrm{C}$ não se 


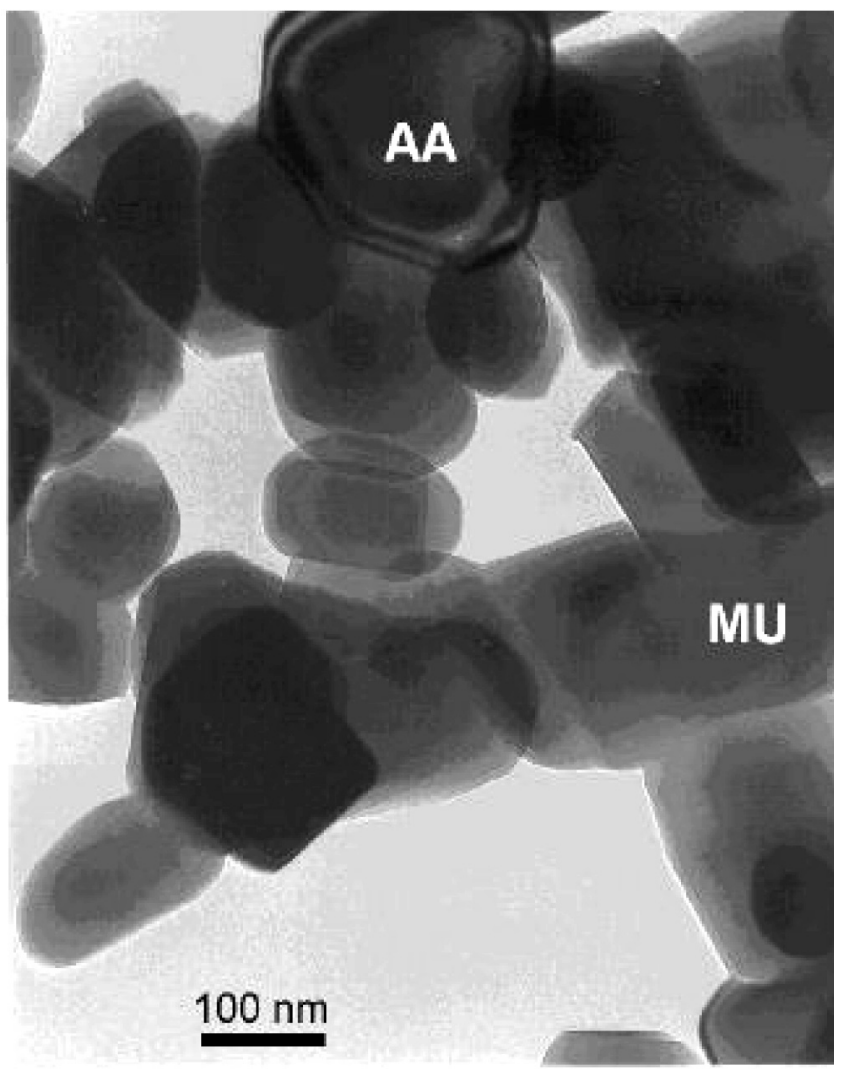

Figura 10: Argila Batalha após queima a $1500{ }^{\circ} \mathrm{C}$ : os cristais de mulita (MU) têm a forma de bastonetes longos e espessos e os cristais de alumina-alfa (AA) são arredondados ou são placas espessas [13].

[Figure 10: Batalha clay after burned at $1500^{\circ} \mathrm{C}$; Mullite crystals $(M U)$ are long and thick rods while alpha-alumina crystals (AA) are rounded for thick plates [13].]

observou reflexões de mulita e alumina-alfa, a partir de 1300 e $1400{ }^{\circ} \mathrm{C}$ observou-se o aumento relativo de mulita, em formas de ripas como mostrado na Fig. 9, pela reação entre sílica não-cristalina e cristobalita (se houver se formado em algum quartzo original) com alumina-alfa. Esta alumina cresce em teor até $1300{ }^{\circ} \mathrm{C}$ e a partir dessa temperatura decresce até $1500{ }^{\circ} \mathrm{C}$, contemplando a afirmação de reação para formação de mulita. As linhas de quartzo se mantiveram praticamente constantes, porém após $1100{ }^{\circ} \mathrm{C}$ e $1200{ }^{\circ} \mathrm{C}$ desaparecem, não sendo detectada cristobalita nessa faixa. Até o aquecimento a $1500{ }^{\circ} \mathrm{C}$ os cristais ripiformes de mulita aumentam em número a partir da reação entre cristobalita e alumina-alfa, Fig. 10.

\section{Tamanho de grãos}

Otamanhode grãotambém teminfluêncianacaracterística mecânica da peça cerâmica, tanto para formação de trincas como facilidade de acomodação, o que implica em densidade de empacotamento [2-5]. A densidade de empacotamento de argilas fabricadas com diferentes tipos granulométricos de pós de alumina foi analisada experimentalmente [14].
Segundo os resultados obtidos, misturas que apresentam sistemas "finos" (“AR", "-500" e "-230”) segundo o sistema de numeração mesh (ASTM E 11-87), apresentaram menor densidade de empacotamento com $1,5 \mathrm{~g} / \mathrm{cm}^{3}$ e o máximo encontrado foi para os sistemas "Médios" ("-500", “$100+140 "$ e "-16+20") com 2,2 g/cm³ . Para combinações de granulometría, o autor verificou que a combinação que assimilou mais empacotamento foi a "Finos Optm." ("AR", “-500” e “-230”). Verificaram-se os efeitos de utilização de diferentes tamanhos de quartzo nas propriedades mecânicas de monoporosas [15]. Constatou-se que o aumento do teor de tamanho de partícula deste mineral acarreta em aumento do coeficiente de dilatação térmica linear e uma redução na resistência mecânica do produto e o módulo de resistência à flexão também é prejudicado com o aumento do tamanho utilizado.

\section{CONCLUSÕES}

A forma de fabricação do material cerâmico influencia diretamente nas propriedades finais do produto. Desde a composição química das matérias primas utilizadas até a forma de queima garantes propriedades distintas ao material.

As fases cristalinas como mulita são de imensa importância para a resistência mecânica da cerâmica e sua quantidade varia de acordo com a temperatura de queima.

Alguns dos principais problemas em corpos cerâmicos são surgimentos de trincas e porosidade indesejada, que se formam respectivamente a partir da diferença do coeficiente de dilatação entre as partículas de fases cristalinas com a matriz e presença de material orgânico na massa cerâmica durante a queima. As trincas têm grande influência negativa na resistência mecânica da porcelana e a porosidade pode prejudicar na qualidade do material como resistência mecânica e tenacidade à fratura.

Como a gama de variáveis é muito grande para a fabricação de porcelanas, pode-se na indústria aperfeiçoar processos a ponto de garantir melhores propriedades possíveis com a correção de imperfeições e utilização da melhores combinações de matérias primas para cada finalidade do material assim como as melhores técnicas de fabricação.

\section{REFERÊNCIAS}

[1] C. Pagani, C. B. Miranda, M.C. Bottino, J. Appl. Oral Sci. 11, 1 (2003) 69-75.

[2] S. R. Bragança, C. P. Bergmann, Cerâmica 50 (2004) 291-299.

[3] R. P. S. Dutra, L. R. de Araújo Pontes, Cerâmica 48 (2002) 308 .

[4] S. L. Correia, D. Hotza, A. M. Segadães, Cerâmica 51 (2005) 230-238.

[5] S.R. Bragança, C. P. Bergmann, Cerâmica 50 (2004) 145-155.

[6] Van Vlack, L. Hall, Propriedades dos materiais cerâmicos, 
Ed. Edgard Blucher, S. Paulo, SP (1973) p.220.

[7] H. N. Yoshimura , A. L. Molisani, G. R. Siqueira, A. C. de Camargo, N. E. Narita, P. F. César, H. Goldenstein, Cerâmica 51 (2005) 239-251.

[8] A. Chatterjee, S. Chitwadgi, M. Kulkarni, A. K. Kaviraj, Cerâmica Industrial 6, 5 (2001) 23-26.

[9] E. Sanchez, M. J. Orts, J. García-Tem, V. Cantavella, Cerâmica Industrial 6, 5 (2001) 15-22.

[10] M. O. Carlos, J. R. Garcia, I. R. Oliveira, R. Salomão, V. C. Pandolfelli, Cerâmica 50 (2005) 78-84.

[11] E. Quinteiro, A. O. Boschi, F. J. S. Arantes, T. Manfredini, C. Leonelli, C. Siligardi, Cerâmica Industrial 7, 1 (2002) 41-43.

[12] M. F. Pinto, S. J. G. Sousa, J. N. F. Holanda. Cerâmica 51 (2005) 225-229.

[13] H. S. Santos, P. Kiyohara, A. C. V. Coelho, P. S. Santos,
Cerâmica 52 (2006) 125-137.

[14] A. P. Silva, A. M. Segadães, T. C. Devezas, Cerâmica 50 (2004) 345-354.

[15] R. T. Zauberas, H. G. Riella, Cerâmica Industrial 6, 2 (2001) 40-45.

[16] L. Sánchez-Muñoz, S. da S. Cava, C. A. Paskocimas, E. Cerisuelo, E. Longo, J. B. Carda, Cerâmica 48 (2002) 306.

[17] F. R. Albuquerque, S. J. G. Lima, C. A. Paskocimas, E. Longo, A. G. Souza, I. M. G. Santos, Cerâmica 52 (2006) 185-192.

[18] S. R. Teixeira, S. A. de Souza, M. A. L. Nobre, Cerâmica 50 (2004) 315.

[19] A. Rendtel, H. Hübner, C. Pagliosa Neto, R. T. T. Noronha, U. Mattos, Cerâmica Industrial 2, 3-4 (1997) 6-9. [20] C. C. Osawa, C. A. Bertran, J. Braz. Chem. Soc. 16, 2 (2005) 251-258.

(Rec. 16/01/2008, Rev. 17/04/2008, Ac. 25/04/2008) 